\title{
Stomatin-like protein 2 induces metastasis by regulating the expression of a rate-limiting enzyme of the hexosamine biosynthetic pathway in pancreatic cancer
}

\author{
DANG CHAO $^{1}$, KYOHEI ARIAKE ${ }^{1}$, SATOKO SATO ${ }^{2}$, HIDEO OHTSUKA ${ }^{1}$, TATSUYUKI TAKADATE ${ }^{1}$, \\ MASAHARU ISHIDA ${ }^{1}$, KUNIHIRO MASUDA ${ }^{1}$, SHIMPEI MAEDA ${ }^{1}$, TAKAYUKI MIURA ${ }^{1}$, \\ KATSUTAKA MITACHI ${ }^{1}$, XUN JING YU ${ }^{1}$, FUMIYOSHI FUJISHIMA ${ }^{2}$, MASAMICHI MIZUMA ${ }^{1}$, \\ KEI NAKAGAWA ${ }^{1}$, TAKANORI MORIKAWA ${ }^{1}$, TAKASHI KAMEI ${ }^{1}$ and MICHIAKI UNNO ${ }^{1}$ \\ ${ }^{1}$ Department of Surgery, Tohoku University Graduate School of Medicine; \\ ${ }^{2}$ Department of Pathology, Tohoku University Hospital, Seiryo-machi, Aoba-ku, Sendai 980-8574, Japan
}

Received September 16, 2020; Accepted January 8, 2021

DOI: $10.3892 /$ or.2021.8041

\begin{abstract}
Stomatin-like protein 2 (SLP-2) is associated with poor prognosis in several types of cancer, including pancreatic cancer (PC); however, the molecular mechanism of its involvement remains elusive. The present study aimed to elucidate the role of this protein in the development of PC. Human PC cell lines AsPC-1 and PANC-1 were transfected by a vector expressing SLP-2 shRNA. Analyses of cell proliferation, migration, invasion, chemosensitivity, and glucose uptake were conducted, while a mouse xenograft model was used to evaluate the functional role of SLP-2 in PC. Immunohistochemical analysis was retrospectively performed on human tissue samples to compare expression between the primary site $(n=279)$ and the liver metastatic site $(n=22)$. Furthermore, microarray analysis was conducted to identify the genes correlated with SLP-2. In vitro analysis demonstrated that cells in which SLP-2 was suppressed exhibited reduced cell motility and glucose uptake, while in vivo analysis revealed a marked decrease in the number of liver metastases. Immunohistochemistry revealed that SLP-2 was increased in liver metastatic sites. Microarray analysis indicated that this protein regulated the expression
\end{abstract}

Correspondence to: Dr Kyohei Ariake, Department of Surgery, Tohoku University Graduate School of Medicine, 1-1 Seiryo-machi, Aoba-ku, Sendai 980-8574, Japan

E-mail: ariake@surg.med.tohoku.ac.jp

Abbreviations: EMT, epithelial-mesenchymal transition; GFPT2, glutamine-fructose-6-phosphate transaminase 2; HBP, hexosamine biosynthesis pathway; IRS, immunoreactive score; NAC, neoadjuvant chemotherapy; PC, pancreatic cancer; RT-qPCR, reverse transcription-quantitative polymerase chain reaction; SIMH, stress-induced mitochondrial hyperfusion; SLP-2, stomatin-like protein 2

Keywords: stomatin-like protein 2, glutamine-fructose-6-phosphate transaminase 2, liver metastasis, pancreatic cancer of glutamine-fructose-6-phosphate transaminase 2 (GFPT2), a rate-limiting enzyme of the hexosamine biosynthesis pathway. SLP-2 contributed to the malignant character of PC by inducing liver metastasis. Cell motility and glucose uptake may be induced via the hexosamine biosynthesis pathway through the expression of GFPT2. The present study revealed a new mechanism of liver metastasis and indicated that SLP-2 and its downstream pathway could provide novel therapeutic targets for PC.

\section{Introduction}

Pancreatic cancer (PC) is one of the most aggressive types of cancer and its prognosis is particularly poor, among gastrointestinal cancers (1). The main reasons for this are late diagnosis and early recurrence, even after curative resection $(2,3)$. Our previous research demonstrated that, among several types of recurrence, prognosis after peritoneal recurrence and liver metastasis was markedly poor compared with other types of recurrence (3). Previous studies have also revealed that these malignant recurrences may be predicted by measuring the glucose activity of cancer cells via the maximum standardized uptake values (SUVmax) obtained from 18-fluorodeoxyglucose positron emission tomography/computed tomography (18F-FDG PET/CT) $(4,5)$. The data suggest that high glucose uptake promotes metastasis of PC cells, causing poor prognosis. However, the detailed mechanism of metastasis remains unclear.

Stomatin-like protein 2 (SLP-2) is mainly located in the mitochondrial inner membrane $(6,7)$. It has been reported to play important roles in regulating mitochondrial membrane stability (7), the formation of mitochondrial respiratory chain super-complexes (8), and in modulating mitochondrial sodium-calcium exchange (9). SLP-2 is also required for stress-induced mitochondrial hyperfusion (SIMH) and its expression is upregulated under conditions of mitochondrial stress (10). This stress condition stimulates mitochondrial biogenesis and function (11), providing the energetic requirements of activation. 
Several previous studies have demonstrated that increased SLP-2 expression induces poor prognosis (12-22). An increasing number of studies have revealed that SLP-2 is implicated in tumor progression and development. The depletion of SLP-2 has been revealed to inhibit the capability of cells to proliferate in colorectal cancer and esophageal squamous cell carcinoma $(15,23)$. Migration and invasion activities have also been revealed to be inhibited after SLP-2 suppression in glioma and liver cancer $(18,24)$. Furthermore, SLP-2 inhibited chemotherapy-induced apoptosis in cervical cancer and in head and neck squamous cell carcinoma $(22,25)$. These findings indicated that the role and the mechanism of SLP-2 in inducing poor prognosis differs according to the origin of the cancer.

It was previously reported by our research group that SLP-2 is a novel prognostic biomarker of PC, based on the results of proteomic analysis (26). However, the function and molecular mechanism of SLP-2 in PC had not been thoroughly explored to date, and no other correlation between SLP-2 and PC had been reported.

The aim of the present study was to explore the function of SLP-2 in PC, using in vitro and in vivo assays. The level of SLP-2 expression at metastatic sites compared to that at primary sites was analyzed, to evaluate its metastatic potential.

\section{Materials and methods}

Antibodies, reagents, and cell lines. Antibodies against SLP-2 were purchased from ProteinTech Group, Inc. (cat. no. 10348-1-AP); GAPDH from Cell Signaling Technology, Inc. (product no. 2118S); GFPT2 from Abcam (product code ab190966); and anti-rabbit IgG as a secondary antibody (cat. no. A0545) was obtained from Sigma-Aldrich; Merck KGaA. The cell lines AsPC-1, BxPC-3, SUIT-2, and SW1990 were purchased from the American Type Culture Collection. The cell line PANC-1 was obtained from RIKEN and MIA-PaCa2 was provided from Cell Resource Center for Biomedical Research, Institute of Development, Aging and Center, Tohoku University (Sendai, Japan). Cells were expanded within 3 passages after being purchased, and multiple lots were stocked at $-80^{\circ} \mathrm{C}$. Mycoplasma contamination check tests were performed using e-Myco plus Mycoplasma PCR Detection Kit (iNtRON Biotechnology, Inc.). Cells were used at least $<20$ passages, but were not independently authenticated.

Transfection with short hairpin (sh)RNA. The sequences of SLP-2 shRNAs are presented in Table SI. The shRNAs were inserted into pBAsi-hU6 NEO plasmids (cat. no. 3227; Takara Bio, Inc.), which carry a neomycin resistance gene. Lipofectamine 2000 reagent (cat. no. 11668019; Thermo Fisher Scientific, Inc.) was used for plasmid transfections into PANC-1 and AsPC-1, according to the manufacturer's protocol. In short, $20 \mu$ g plasmids with $2 \mathrm{ml}$ Opti-MEM (cat. no. 31985070; Thermo Fisher Scientific, Inc.) and $30 \mu 1$ Lipofectamine 2000 with Opti-MEM were produced. Then, these mediums were combined at room temperature for $20 \mathrm{~min}$. After mixture, this medium was placed in a $10-\mathrm{mm}$ dish and cells were cultured at $37^{\circ} \mathrm{C}$ for $12 \mathrm{~h}$. After exposure, the medium was changed to RPMI-1640 medium supplemented with $1,000 \mathrm{mg} / \mathrm{ml}$
Geneticin ${ }^{\circledR}$ (cat. no. 10131-027; Thermo Fisher Scientific, Inc.). The blank pBAsi-hU6 NEO plasmid was also transfected as a negative control. Transfected clones, on RPMI-1640 medium supplemented with $1,000 \mathrm{mg} / \mathrm{ml}$ Geneticin ${ }^{\circledR}$, were selected over a period of 3 weeks, after which a single colony was selected and cultured.

Reverse transcription-quantitative polymerase chain reaction $(R T-q P C R)$. Total RNA was isolated from cancer cells using the Nucleospin RNA kit (cat. no. 740955; Takara Bio, Inc.). Reverse transcription reactions were set up using PrimeScript RT Master Mix (cat. no. RR036A; Takara Bio, Inc.), according to the manufacturer's protocol under the following thermocycling conditions: $37^{\circ} \mathrm{C}$ for $15 \mathrm{~min}$, followed by $85^{\circ} \mathrm{C}$ for $5 \mathrm{sec}$, and the products were used as templates for RT-qPCR. The gene products were amplified using TB Green Premix Ex Taq II, ROX Plus (cat. no. RR82LR; Takara Bio, Inc.) under the following thermocycling conditions: $95^{\circ} \mathrm{C}$ for $30 \mathrm{sec}$, followed by 40 cycles at $95^{\circ} \mathrm{C}$ for $5 \mathrm{sec}$ for denaturation and $60^{\circ} \mathrm{C}$ for $30 \mathrm{sec}$ for annealing/extension. The expression levels of each target gene were calculated using the $2^{-\Delta \Delta C q}$ method (27). Relative quantities were calculated after normalizing for GAPDH expression. The primers used in the present study are presented in Table SI.

RNA preparation and microarray analyses. RNA isolates were obtained from AsPC-1cont, AsPC-1sh1, and AsPC-1sh2 cells using the Nucleospin RNA kit and assessed for quality using a NanoDrop spectrophotometer (Thermo Fisher Scientific, Inc.). The GeneChip ${ }^{\mathrm{TM}}$ WT PLUS Reagent Kit (cat. no. 902281; Thermo Fisher Scientific, Inc.) was used to prepare the RNA samples; for whole-transcriptome expression analyses, the Clariom ${ }^{\mathrm{TM}} \mathrm{S}$ assay (cat. no. 902926; Thermo Fisher Scientific, Inc.) was used. The GeneChip was analyzed using a GeneChip $^{\text {TM }}$ Scanner 3000 7G system, while the gene expression was analyzed using a GeneTitan ${ }^{\mathrm{TM}}$ instrument (both from Thermo Fisher Scientific, Inc.). The transcriptomic array data set was analyzed using the Transcriptome Analysis Console software Ver 4.0 (Thermo Fisher Scientific, Inc.). Genes with fold-changes of $<-20$ or $>20$ and with a P-value $<0.05$ in comparisons between AsPC-1cont and AsPC-1sh1 or AsPC-1sh2 were selected as candidate genes associated with SLP-2 expression. The data of microarray analysis are available in Gene Expression Omnibus at https://www.ncbi.nlm. nih.gov/geo/query/acc.cgi?acc=GSE162981.

Western blotting. Cells were lysed with RIPA buffer (Thermo Fisher Scientific, Inc.), and the concentrations of protein samples were evaluated using a BCA kit (Thermo Fisher Scientific, Inc.). A total of $20 \mu \mathrm{g}$ of proteins were separated on SDS-PAGE gels (4-15\%) and subsequently transferred onto PVDF membranes (Bio-Rad Laboratories, Inc.). The membranes were then blocked at room temperature for $1 \mathrm{~h}$ using Western Blocking Reagent (Thermo Fisher Scientific, Inc.) and incubated with primary antibodies (SLP-2 and GFPT-2) at room temperature for $1 \mathrm{~h}$ at dilutions of 1:2,000. PVDF membranes were then incubated with secondary antibodies at room temperature for $30 \mathrm{~min}$ (HRP-conjugated) at dilutions of 1:5,000, and signals were detected using the Clarity ECL Western Substrate (cat. no. 1705062; Bio-Rad 
Laboratories, Inc.). Protein bands were visualized using an ImageQuant LAS 4000 mini system (GE Healthcare; Cytiva).

Cell proliferation assay. A total concentration of $5 \times 10^{3}$ cells was seeded in 96-well plates and cultured with $100 \mu \mathrm{l}$ of RPMI-1640 medium with $10 \%$ FBS, $1 \%$ penicillin, and $1,000 \mathrm{mg} / \mathrm{ml}$ geneticin. The MTS assays were performed using CellTiter 96-well assay reagent (cat. no. G358B; Promega Corporation), according to the manufacturer's recommendations. The absorbance was measured at a wavelength of $490 \mathrm{nM}$. The experiment was performed in triplicate.

Wound-healing assay. Cells grown on petri dishes were starved in serum-free medium for $24 \mathrm{~h}$ and then scratched with the tip of a sterile $10-\mu l$ pipette. Following this, the cultured cells were rinsed and incubated with RPMI-1640 medium containing $10 \%$ FBS, $1 \%$ penicillin, and $1,000 \mathrm{mg} / \mathrm{ml}$ geneticin. After $12 \mathrm{~h}$, the wound-closure distances were measured at three independent wound sites per group using a light microscope, and the average was calculated. The data are expressed as a relative index considering the differences in wound length at the initial time-point. The assays were performed in triplicate.

Transwell cell migration and invasion assay. Transwell assays were performed using the QCM 24-well Fluorometric Cell Migration Assay kit (cat. no. ECM509; EMD Millipore) for the migration assay and the QCM 24-well Cell Invasion Assay kit using Matrigel ${ }^{\circledR}$-coated Transwell chambers (cat. no. ECM554; EMD Millipore) for the invasion assay. The cells were pretreated with serum-free medium for $24 \mathrm{~h}$, and then harvested in a serum-free medium. Then, 300- $\mu$ 1 cell samples were transferred to the upper chambers of the kit $\left(1 \times 10^{6} / \mathrm{ml}\right)$, and $500 \mu \mathrm{l}$ of medium containing $10 \%$ FBS for the migration assay and 20\% FBS for the invasion assay was added to the lower chamber. After incubation for $24 \mathrm{~h}$, the cells were dislodged using $225 \mu \mathrm{l}$ of cell detachment solution from the underside of the upper chamber for $30 \mathrm{~min}$ at $37^{\circ} \mathrm{C}$. Thereafter, the samples were stained with sufficient lysis buffer/dye solution for $15 \mathrm{~min}$ at $20-25^{\circ} \mathrm{C}$. The results were quantified using a fluorescence plate reader fitted with a $480 / 520 \mathrm{~nm}$ filter. The data are expressed using a relative index, by setting the migrated or invasive control cells to $100 \%$. This assay was performed in triplicate.

Cytotoxicity assay. Cells were plated at $5 \times 10^{3}$ cells/well in 96-well plates. After $24 \mathrm{~h}$, the medium was replaced by another containing from $1 \times 10^{-4}$ to $1 \times 10^{3} \mu \mathrm{M}$ gemcitabine hydrochloride (FUJIFILM WAKO Pure Chemical Corporation). Cells were cultured for $120 \mathrm{~h}$ and then cell viability was measured by MTS assays using the CellTiter 96-well assay reagent (Promega Corporation), as recommended by the manufacturer. The absorbance was measured at a wavelength of $490 \mathrm{nM}$. Each test was carried out in triplicate.

Glucose uptake assay. The Glucose Uptake-Glo Assay (cat.no.J1342; Promega Corporation) was applied to cells grown in 96-well plates. Glucose-free media were used throughout the steps of this assay. A total of $50 \mu \mathrm{l}$ of $1 \mathrm{mM} 2$-deoxyglucose was added to each well to initiate the assay. The uptake reaction was stopped according to the manufacturer's protocol, after $2 \mathrm{~h}$ of incubation. The luminescence was recorded using 1 -sec integration on a luminometer. These experiments were performed in triplicate.

In vivo experiments. The Institutional Animal Experiment Committee of Tohoku University (Sendai, Japan) approved the present study protocol on September 20, 2017. AsPC-1 stable cells (blank or shRNA-transfected) were harvested from $80 \%$ confluent culture dishes, resuspended in PBS, and maintained on ice. Six-week-old SCID mice (C.B-17/Icr-scid/scid $\mathrm{Jcl}$; male; weight, $23 \mathrm{~g}$ ) were used for this experiment. A triple-mixed anesthetic was prepared, consisting of medetomidine $(1 \mathrm{mg} / \mathrm{ml})$, midazolam $(5 \mathrm{mg} / \mathrm{ml})$, and butorphanol $(5 \mathrm{mg} / \mathrm{ml})$; this solution was injected intraperitoneally into the mice ( $0.1 \mathrm{ml}$ per $10 \mathrm{~g}$ body weight per mouse). An incision was made to exteriorize the spleens, to inject $5 \times 10^{5}$ cells per $100 \mu \mathrm{l}$ slowly into them. A cotton swab was held over the injection site for at least $5 \mathrm{~min}$ to avoid leakage and bleeding. After confirming that the bleeding had stopped, the spleens were returned into the peritoneal cavities, and the abdominal wounds were closed. Six weeks after the injection, the mice were sacrificed using $60 \mu \mathrm{l}$ of pentobarbital $(50 \mathrm{mg} / \mathrm{ml})$, and their livers were removed. The number of metastatic sites on the liver surface was counted. Three biological replicates were used for each experiment.

Immunohistochemistry. All specimens for immunohistochemistry were fixed for $24 \mathrm{~h}$ in $10 \%$ formalin and embedded in paraffin wax. Two specialists from the Department of Pathology of Tohoku University performed the SLP-2 immunostaining procedures and scored the immunoreactivity. The staining intensity combined with the positive cell percentages were used to obtain a semiquantitative analysis of immunoreactivity. The staining intensity was scored as 0 (negative), 1 (weak), 2 (moderate), or 3 (strong) (Fig. S1); the positive cell percentage was scored as $0(0 \%), 1(<10 \%), 2(10-50 \%), 3(51-80 \%)$, or $4(>80 \%)$. The staining intensity and positive cell percentages were multiplied to evaluate the immunoreactive scores (IRS), which ranged from 0 to 12 .

Clinical data concerning 279 patients (166 male and 113 female patients; aged 27-88 years old; median age, 67 years) with pancreatic ductal adenocarcinoma, who underwent surgical resection between January 1, 2006 and December 31, 2014, were obtained from records at our institute on January 1, 2020. The study included resectable to unresectable PDAC, NAC and non-NAC as well as R0 to R2 patients. Radiographic resection status was defined by the National Comprehensive Cancer Network guidelines for pancreatic cancer, Version 1 (2020) (28) and pathological status was diagnosed by the Union for International Cancer Control TNM classification (7th edition) (29). The Institutional Review Board of Tohoku University (Sendai, Japan) approved the present study design on May 25, 2016 (2016-1-151). As this was a retrospective study, the requirement for informed consent was waived and an opt-out method was used instead. The present study was conducted in accordance with the STROBE guidelines (www.strobe-statement.org) (30).

Statistical analysis. Statistical analysis was conducted on the JMP pro software v14 (SAS Institute). Data are 
A

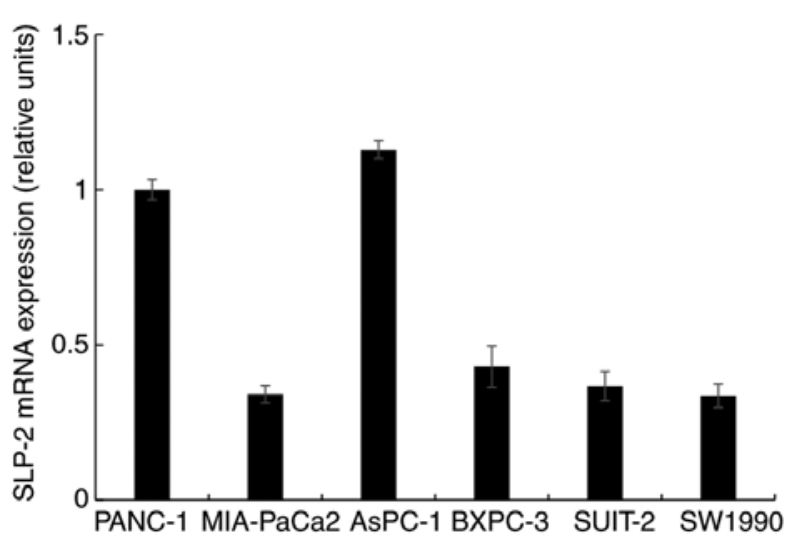

$\mathrm{B}$
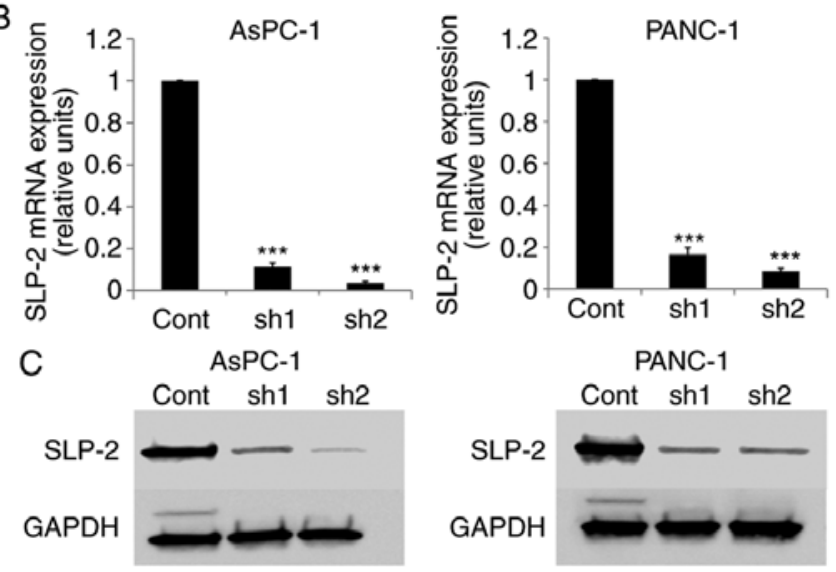

Figure 1. SLP-2 expression in PC cells. (A) SLP-2 expression in PANC-1, MIA-PaCa2, AsPC-1, BXPC-3, SUIT-2, and SW1990 cells were evaluated by RT-qPCR. Relative expression level was calculated after normalizing to GAPDH expression. (B and C) SLP-2 expression suppressed by shRNA transfection in both AsPC-1 and PANC-1 cells. (B) RT-qPCR and (C) western blotting. GAPDH was an internal control. RT-qPCR and western blotting were performed thrice. ${ }^{* * * *} \mathrm{P}<0.001$. SLP-2, stomatin-like protein 2; PC, pancreatic cancer; RT-qPCR, reverse transcription-quantitative polymerase chain reaction; cont, control; sh, short hairpin.

expressed as the mean \pm standard deviation (SD). Student's t-test was used to compare the means of two groups, while ANOVA followed by Dunnett's post hoc test were used to compare the means of multiple experimental groups. The binomial variables of clinicopathological factors were compared using Pearson's chi-square test. P-values $<0.05$ were considered to indicate a statistically significant difference.

\section{Results}

Cloning a stable SLP-2 silencing cell line. SLP-2 expression was evaluated thrice in six types of PC cell lines (PANC-1, MIA-PaCa2, AsPC-1, BXPC-3, SUIT-2, and SW1990) (Fig. 1A). SLP-2 expression in AsPC-1 and PANC-1 cells was relatively high compared with that in other cell lines; hence, these cell lines were selected for further analysis.

The designed shRNA was inserted into the pBAsi-hU6 NEO plasmid and transfected into AsPC-1 and PANC-1 cells. By RT-qPCR (Fig. 1B) and western blotting (Figs. 1C and S2A), it was revealed that SLP-2 expression was significantly decreased in shRNA-transfected cells.
SLP-2 silencing reduces cell migration and invasion abilities. To evaluate the effect of SLP-2 expression on cell motility, in vitro wound-healing assays were performed (Fig. $2 \mathrm{~A}$ and $\mathrm{B}$ ). The results revealed that wound widths were decreased in AsPC-1sh1 $(\mathrm{P}=0.017)$ and AsPC-1sh2 $(\mathrm{P}<0.001)$ compared with the widths observed in AsPC-1cont cells. Similar results were also revealed in PANC-1sh1 $(\mathrm{P}<0.001)$ and PANC-1sh2 $(\mathrm{P}<0.001)$ cells. In addition, Transwell cell migration assays also demonstrated that the migration abilities of AsPC-1sh1 and AsPC-1sh2 cells were decreased to $30.0 \%(\mathrm{P}<0.001)$ and $34.2 \%(\mathrm{P}<0.001)$, respectively, in comparison with the corresponding migration ability of AsPC-1cont cells (Fig. 2C). The same results were also demonstrated in PANC-1 cells, with migration abilities decreased to $41.6 \%(\mathrm{P}<0.001)$ in PANC-1sh1 and $51.8 \%(\mathrm{P}<0.001)$ in PANC-1sh 2 cells. Furthermore, the results of invasion assay using Matrigel $^{\circledR}$-coated Transwell chambers revealed that the invasive activity of AsPC-1sh1 and AsPC-1sh2 cells was decreased to $67.2 \%(\mathrm{P}=0.002)$ and $67.9 \%(\mathrm{P}=0.002)$, respectively, compared to the corresponding activity level in control cells (Fig. 2D). The results in PANC-1 cells also confirmed a decrease in activity to $35.8 \%(\mathrm{P}<0.001)$ in PANC-1sh1 cells and 44.7\% (P<0.001) in PANC-1sh 2 cells.

Inhibition of SLP-2 expression reduces the glucose uptake in PC cells. Glucose uptake was evaluated in different SLP-2-expressing PC cells. As revealed in Fig. 3A, compared to AsPC-1cont cells, glucose uptake was significantly decreased to $75.6 \%$ in AsPC-1sh1 $(\mathrm{P}=0.042)$ and $75.0 \%$ in AsPC-1sh2 cells $(\mathrm{P}=0.038)$. The same was observed in $\mathrm{PANC}-1$ cells; it was decreased to $46.3 \%$ in PANC-1sh1 $(\mathrm{P}<0.001)$ and to $35.3 \%$ in PANC-1sh 2 cells $(\mathrm{P}<0.001)$ (Fig. $3 \mathrm{~B})$.

SLP-2 does not affect cell proliferation and chemosensitivity to gemcitabine. An MTS assay demonstrated that the cell growth curves were almost identical regardless of the expression of SLP-2 in both AsPC-1 and PANC-1 cells. Additionally, no significant differences were found in the four-day growth rate of cells among AsPC-1cont, AsPC-1sh1 and AsPC-1sh2 cells $(\mathrm{P}=0.944)$ (Fig. S3A). Similar results were revealed among PANC-1cont cells, PANC-1sh1and PANC-1sh2 cells $(\mathrm{P}=0.532)$ (Fig. S3B).

To investigate whether SLP-2 affects the chemosensitivity of PC, cells were treated with different doses of gemcitabine. The present findings revealed no significant differences in the $\mathrm{IC}_{50}$ values of AsPC-1cont $(0.069 \mu \mathrm{M})$, AsPC-1sh1 $(0.066 \mu \mathrm{M})$, and AsPC-1sh2 cells $(0.090 \mu \mathrm{M})(\mathrm{P}=0.713)$ (Fig. S4A). No significant differences were also observed in the $\mathrm{IC}_{50}$ values of PANC-1cont cells $(0.053 \mu \mathrm{M})$, PANC-1sh1 $(0.053 \mu \mathrm{M})$, and PANC-1sh2 cells $(0.053 \mu \mathrm{M})(\mathrm{P}=0.989)$ (Fig. S4B).

SLP-2 expression was significantly positively correlated with liver metastasis in PC. To investigate the role of SLP-2 during liver metastasis, different SLP-2-expressing PC cells were injected into the spleen of SCID mice. A previous study revealed that only AsPC-1 could cause liver metastasis in SCID mice, among several PC cell lines such as PANC-1, MIA PaCa-2, AsPC-1, and BxPC-3 (31). In agreement with the previous study, PANC-1 cells did not cause liver metastasis, even in control cells (data not shown). Therefore, AsPC-1 cells were used to evaluate the potential of SLP-2 to cause liver 


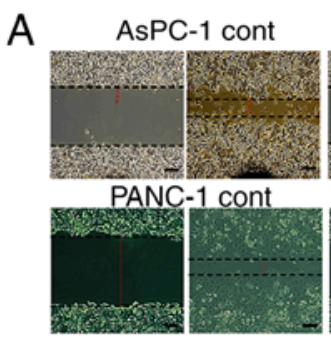

$\mathrm{Oh}$

$12 \mathrm{~h}$
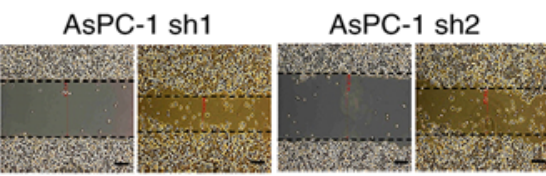

PANC-1 sh

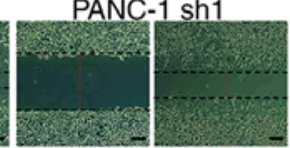

$\mathrm{Oh}$

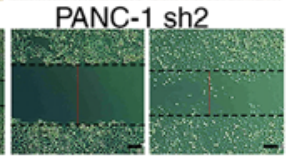

$\mathrm{Oh}$

$12 \mathrm{~h}$
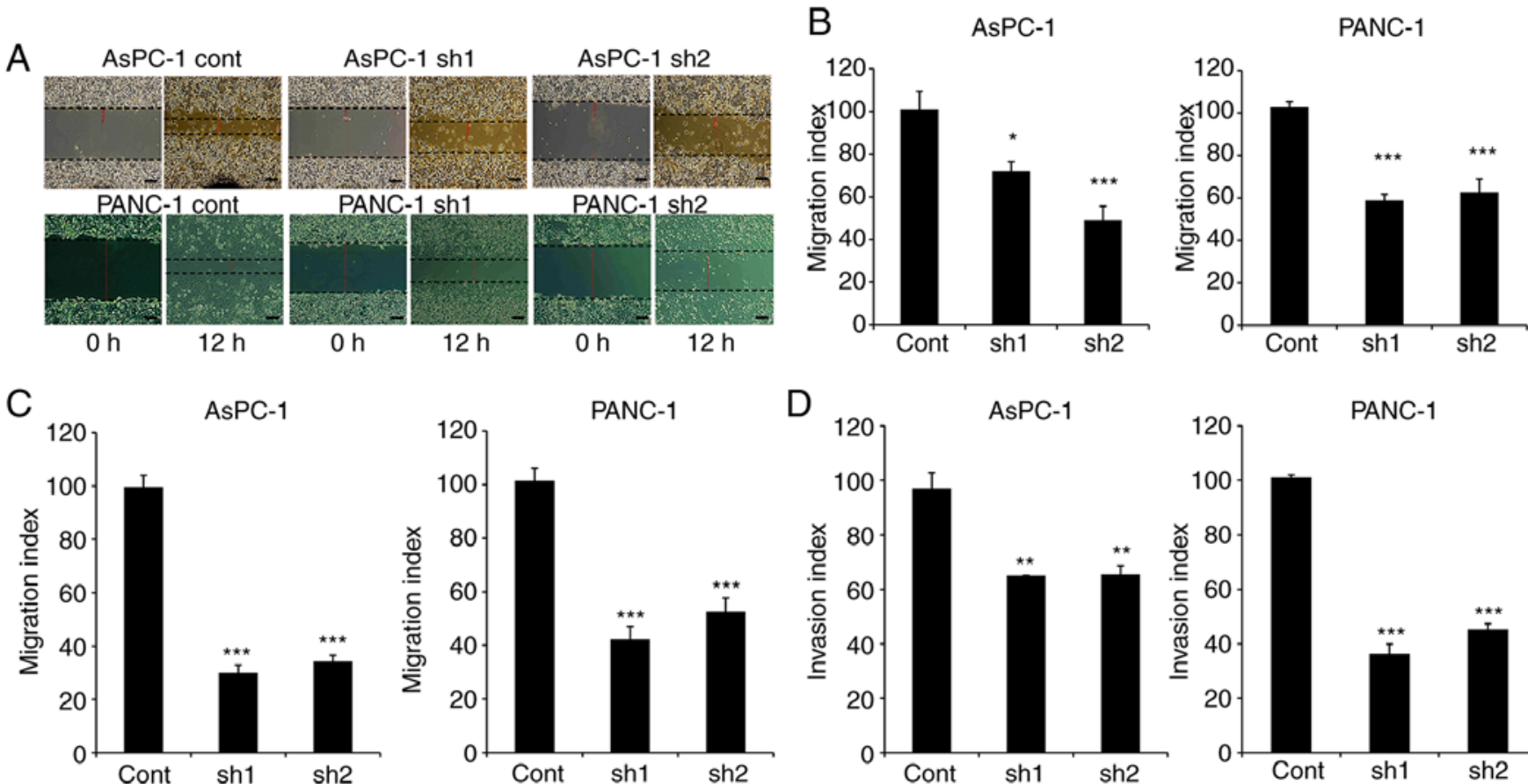

Figure 2. SLP-2 suppression inhibits cancer cell migration and invasion activities. (A and B) Migration activities were assessed by scratch assay using AsPC-1 and PANC-1 cells. The wound closure distances were measured, and the average was calculated. (A) Migrated cancer cells and (B) the relative migration rate of control cells. Scale bar, $20 \mu \mathrm{m}$. (C and D) Transwell assays were also performed to evaluate the migration and invasion activities related to SLP-2 expression. (C) Migrated cells and (D) invasive cells were stained with lysis buffer/dye solution and quantified with a fluorescence plate reader using a $480 / 520$ nm filter. Data are expressed as the mean $\pm \mathrm{SD}$. All experiments were performed thrice. ${ }^{*} \mathrm{P}<0.05,{ }^{* *} \mathrm{P}<0.01$ and ${ }^{* * * *} \mathrm{P}<0.001$. SLP-2, stomatin-like protein 2 ; cont, control; sh, short hairpin.
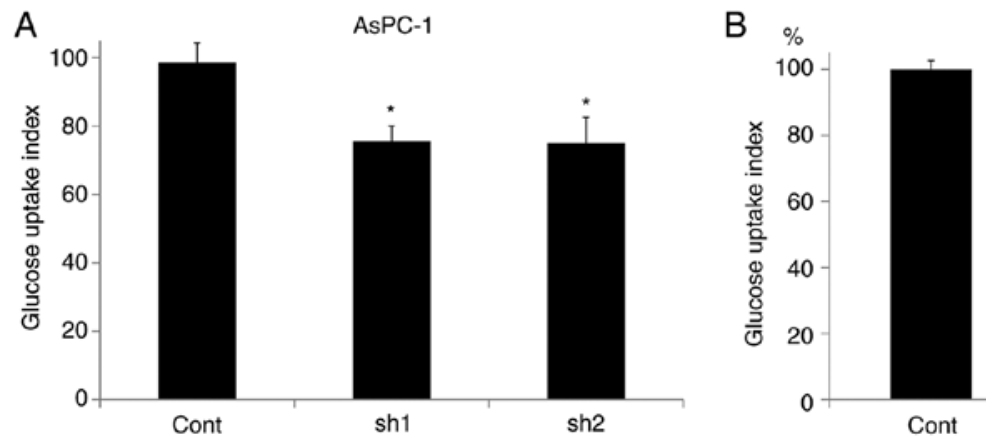

PANC-1

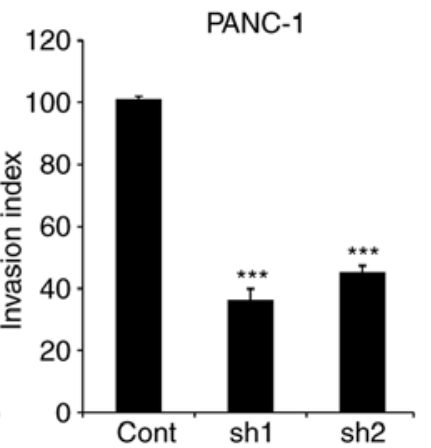

Figure 3. SLP-2 suppression inhibits glucose uptake ability. The glucose uptake ability was evaluated using the Glucose Uptake-Glo Assay kit in differen SLP-2-expressing PC cells. (A and B) SLP-2 silencing reduced the glucose uptake in (A) AsPC-1 cells and (B) PANC-1 cells. Data are expressed as the mean \pm SD. All experiments were performed thrice. ${ }^{*} \mathrm{P}<0.05$ and ${ }^{* * * *} \mathrm{P}<0.001$. SLP-2, stomatin-like protein 2; PC, pancreatic cancer; cont, control; sh, short hairpin.

metastasis. Six weeks after the injections, the mean number of liver metastases was significantly decreased from 22 in the AsPC-1cont cells, to $2.3(\mathrm{P}<0.001)$ in AsPC-1sh1, and 1.6 in AsPC-1sh2 ( $\mathrm{P}<0.001)$ (Fig. 4A and $\mathrm{B})$.

To validate the results of the in vivo analysis, SLP-2 expression level was measured from the primary sites and liver metastatic sites in PC tissue samples from patients, using immunohistochemistry. First, the SLP-2 expression of the two tissues from the group without neoadjuvant chemotherapy (non-NAC) was compared. The IRS was significantly increased in the metastatic site compared with that at the primary site ( 8.9 vs. $5.9 ; \mathrm{P}=0.021$ ) (Fig. 4 C). Next, the IRS of the two sites was compared in patients after neoadjuvant chemotherapy (the NAC group). Similarly, the IRS was significantly increased at the metastatic site compared with that at the primary site (9.6 vs. 7.0; $\mathrm{P}=0.008$ ) (Fig. 4D).

SLP-2 expression is associated with the expression of GFPT2. To define the SLP-2-associating factor in PC cells, a microarray analysis was performed using AsPC-1cont cells and AsPC-1sh1 or AsPC-1sh2 cells. The data of microarray analysis are available in Gene Expression Omnibus at https://www.ncbi.nlm. nih.gov/geo/query/acc.cgi?acc=GSE162981. It was determined that 8 candidate genes were overexpressed by $>20$-fold and 7 genes were downregulated by $>20$-fold in AsPC-1cont cells compared with the corresponding expression levels of the genes in SLP-2-suppressed cells (Fig. 5A). In the present study, the expression of glutamine-fructose-6-phosphate 

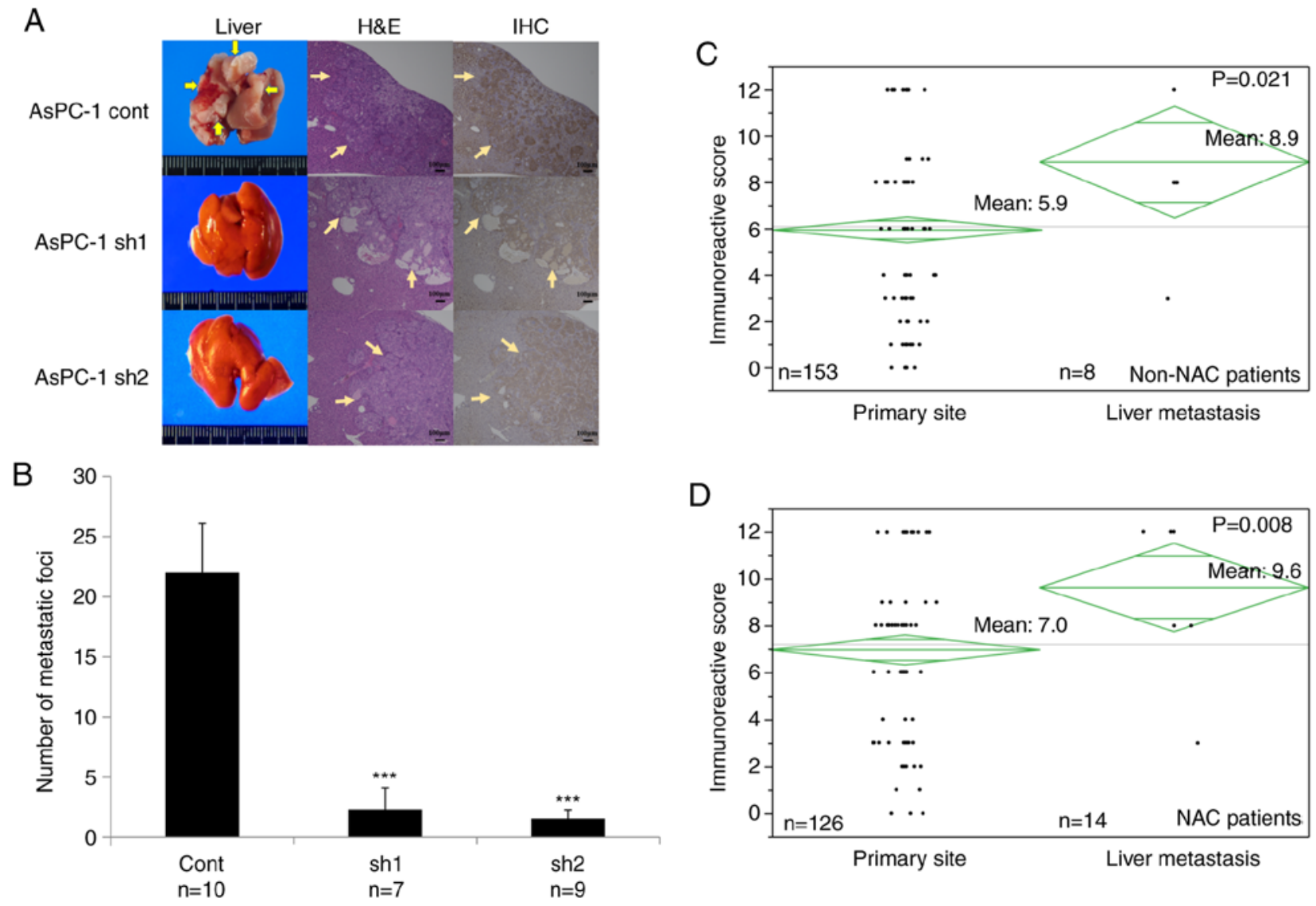

Figure 4. SLP-2 expression promotes liver metastasis in PC. (A and B) Stable cells of AsPC-1 were injected into the spleen of mice, and, after 6 weeks, the number of metastatic foci on the liver surface were counted. (A) Images revealing liver metastasis, hematoxylin and eosin staining, and immunohistochemical analysis of SLP2. Arrows indicate the metastatic tumor. (B) Values are represented by the mean \pm SD. ${ }^{* * *} \mathrm{P}<0.001$. The biological replicate number was 10 for AsPC-1cont cells, 7 for AsPC-1sh1 cells, and 9 for AsPC-1sh2 cells. (C and D) SLP-2 expression level was compared between the primary site and the liver metastatic site using the Immunoreactive Score. (C) SLP-2 expression was compared in the patients without neoadjuvant chemotherapy. The mean score of the liver metastatic site $(\mathrm{n}=8)$ was significantly higher than that of the primary site $(\mathrm{n}=153)(8.9$ vs. 5.9; $\mathrm{P}=0.021)$. (D) SLP-2 expression was compared in the patients undergoing neoadjuvant chemotherapy. The mean score of the liver metastatic site $(n=14)$ was significantly higher than that of the primary site ( $\mathrm{n}=126)$ (9.6 vs. 7.0; $\mathrm{P}=0.008)$. SLP-2, stomatin-like protein 2; PC, pancreatic cancer; cont, control; sh, short hairpin; H\&E, hematoxylin and eosin staining; IHC, immunohistochemical analysis; NAC, neoadjuvant chemotherapy.

A

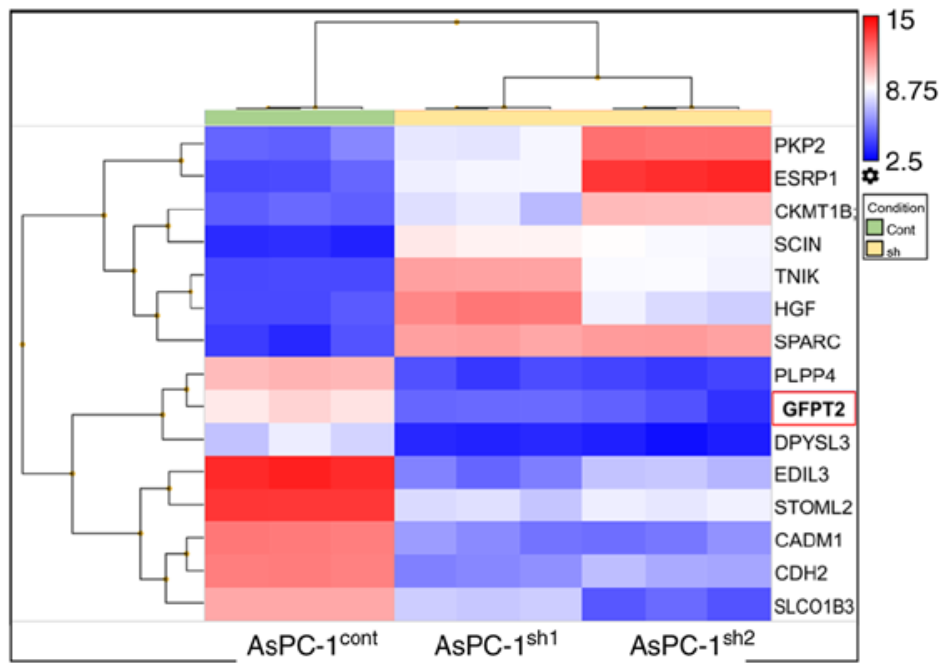

B

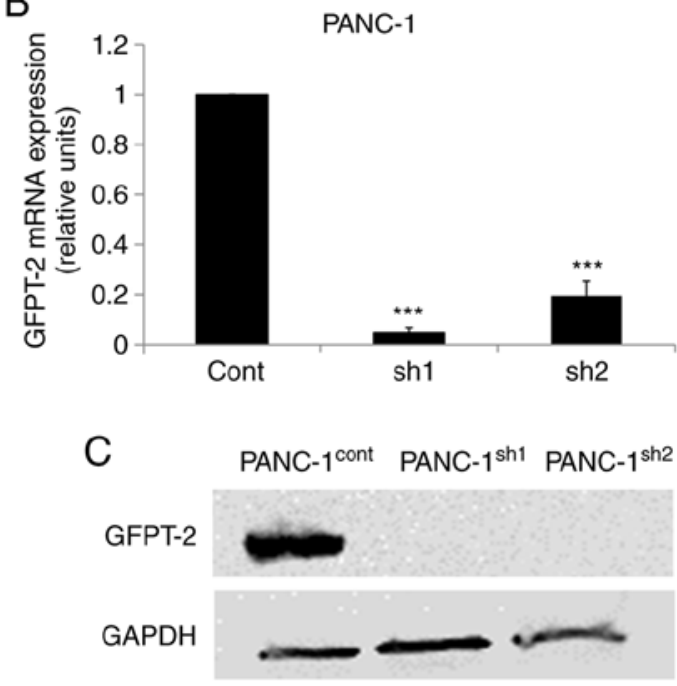

Figure 5. Microarray analysis detects GFPT2 as a new SLP-2-associated factor. (A) Genes with fold-changes $<-20$ or $>20$ and with a P<0.05 were candidate factors associated with SLP-2 expression. Eight upregulated genes and seven downregulated gene were identified in SLP-2-suppressed AsPC-1 cells, compared with the expression levels in the control cells. Green indicates the control group, while yellow indicates the sh group. (B and C) The expression of GFPT2 was decreased in shRNA-transfected PANC-1 cells in both (B) RT-qPCR and (C) western blotting. GAPDH was an internal control. RT-qPCR and western blotting were performed thrice. ${ }^{* * * *} \mathrm{P}<0.001$. GFPT2, glutamine-fructose-6-phosphate transaminase 2; SLP-2, stomatin-like protein 2; RT-qPCR, reverse transcription-quantitative polymerase chain reaction; cont, control; sh, short hairpin. 
Table I. Distribution between non-NAC and NAC patients.

\begin{tabular}{|c|c|c|c|c|c|}
\hline \multirow[b]{2}{*}{ Clinical/pathological variables } & & \multirow[b]{2}{*}{$\begin{array}{c}\text { Total } \\
(n=279)\end{array}$} & \multicolumn{3}{|c|}{$\begin{array}{l}\text { Distribution between non-NAC and } \\
\text { NAC patients }\end{array}$} \\
\hline & & & $\begin{array}{c}\text { non-NAC } \\
(\mathrm{n}=153)\end{array}$ & $\begin{array}{l}\text { NAC } \\
(n=126)\end{array}$ & P-value \\
\hline \multirow[t]{4}{*}{ Resectability } & Resectable & 117 & 88 & 29 & $<0.001$ \\
\hline & Borderline & 138 & 64 & 74 & \\
\hline & Resectable & & & & \\
\hline & Unresectable & 24 & 1 & 23 & \\
\hline \multirow[t]{2}{*}{ Pretreatment CA19-9 (U/ml) } & $>100$ & 119 & 71 & 48 & 0.163 \\
\hline & $\leq 100$ & 160 & 82 & 78 & \\
\hline \multirow[t]{2}{*}{ Tumor position } & $\mathrm{ph}$ & 195 & 102 & 93 & 0.196 \\
\hline & $\mathrm{pbt}$ & 84 & 51 & 33 & \\
\hline \multirow[t]{2}{*}{ Tumor size (mm) } & $>30$ & 138 & 69 & 69 & 0.108 \\
\hline & $\leq 30$ & 141 & 84 & 57 & \\
\hline \multirow[t]{2}{*}{ UICC-T } & 1,2 & 14 & 9 & 5 & 0.141 \\
\hline & 3 & 265 & 144 & 121 & \\
\hline \multirow[t]{2}{*}{ UICC-N } & 0 & 77 & 37 & 40 & 0.371 \\
\hline & 1 & 202 & 116 & 86 & \\
\hline \multirow[t]{2}{*}{ UICC-M } & 0 & 224 & 125 & 99 & 0.176 \\
\hline & 1 & 55 & 28 & 27 & \\
\hline \multirow[t]{2}{*}{ Residual cancer } & R0 & 244 & 134 & 110 & 0.944 \\
\hline & $\mathrm{R} 1,2$ & 35 & 19 & 16 & \\
\hline
\end{tabular}

The UICC-N category describes the presence of regional lymph node metastasis. The UICC-M category describes the presence of distant metastasis. NAC, neoadjuvant chemotherapy; UICC, Union for International Cancer Control. The UICC-T category describes the status of primary tumor.

transaminase 2 (GFPT2) as a new candidate gene associated with SLP-2 expression was evaluated; this is because, from the literature (32-34), it appears that only GFPT2 could regulate cell motility and glucose uptake activity. Expression of the GFPT2 gene was confirmed in PANC-1 cells using RT-qPCR and western blotting and was revealed to be downregulated in SLP-2-suppressed cells (Figs. 5B and C, and S2B).

SLP-2 expression is increased after NAC. Table I reveals the clinicopathological characteristics of both the non-NAC and NAC groups. The distribution between the two groups revealed a significant difference in resectability status. This is because borderline resectable or unresectable cases usually underwent preoperative treatment before surgical resection. To evaluate whether SLP-2 expression differed according to tumor progression, SLP-2 expression was analyzed for each resectability status. For patients in the non-NAC group, the mean IRS did not exhibit significant differences among the three groups ( $\mathrm{R}$ vs. BR vs. $\mathrm{UR}, 6.1$ vs. 5.8 vs. $6.0 ; \mathrm{P}=0.839$ ) (Fig. S5A). The same results were also revealed in the NAC group (R vs. BR vs. UR, 6.3 vs. 7.1 vs. 7.3; P=0.534) (Fig. S5B). These results demonstrated that SLP-2 expression did not differ according to the resectability status. However, when the SLP-2 expression profile of the non-NAC group was compared with that of the NAC group, the IRS was significantly higher in the
NAC group (5.9 vs. 7.0; $\mathrm{P}=0.019)$ (Fig. S5C). All these results demonstrated that NAC itself may increase SLP-2 expression.

Gemcitabine exposure increases SLP-2 expression in $P C$ cells. To evaluate the hypothesis that NAC itself promotes the expression of SLP-2, its expression was evaluated after exposure to gemcitabine. SLP-2 expression was significantly increased in PANC-1 cells after exposure to 100 or $1,000 \mu \mathrm{M}$ gemcitabine (Fig. 6A). Next, the effect of SLP-2 on GFPT2 expression was analyzed. GFPT2 expression was also significantly enhanced after gemcitabine exposure, and inhibition of SLP-2 suppressed the expression of GFPT2 (Fig. 6B). These results demonstrated that gemcitabine promoted SLP-2 expression in PC cells, and subsequently increased the expression of GFPT2. Suppression of SLP-2 could also inhibit gemcitabine-induced GFPT2 expression.

\section{Discussion}

In the present study, with regard to PC, suppression of SLP-2 did not alter the cell proliferation or chemosensitivity to gemcitabine. Conversely, it reduced cell migration and invasion activities. Suppression of SLP-2 significantly decreased the number of liver metastases in the mouse xenograft model. Furthermore, immunohistochemical results revealed that 

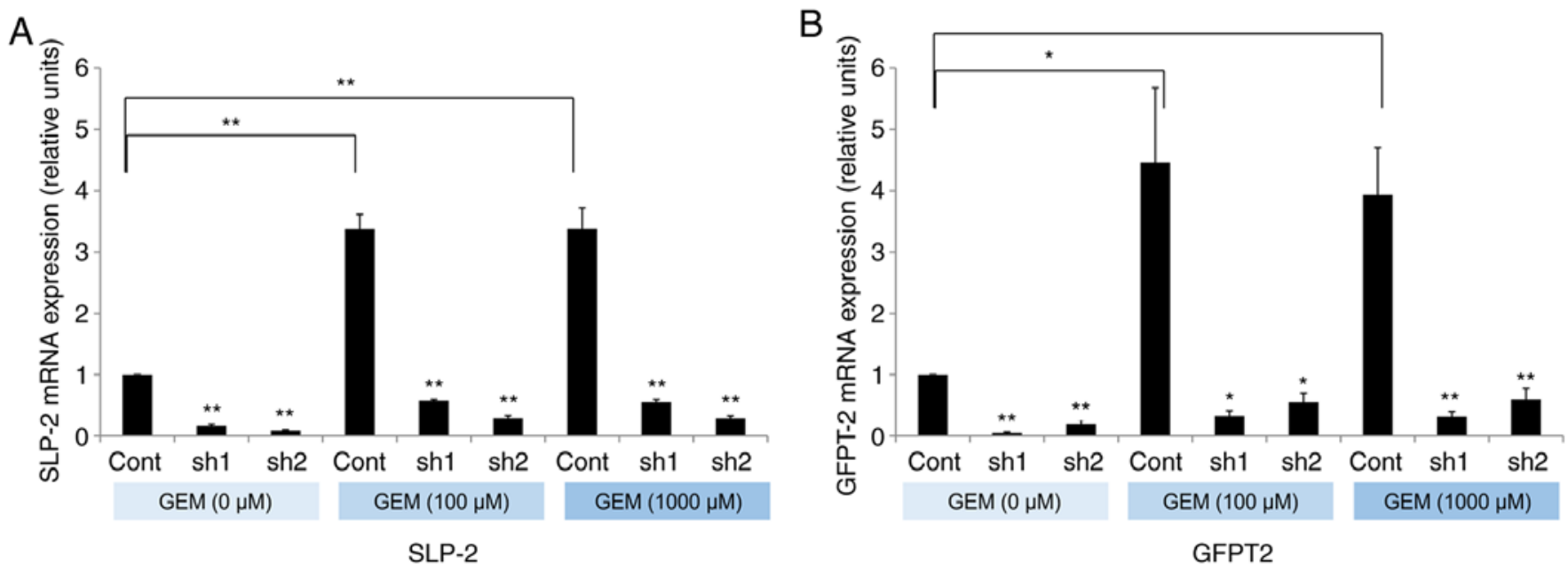

Figure 6. Gemcitabine promotes SLP-2 expression and GFPT2 expression. (A and B) PC cell lines were exposed to two doses of gemcitabine. After $120 \mathrm{~h}$, the expression of SLP-2 and GFPT2 was measured by RT-qPCR. (A) SLP-2 expression was significantly increased after gemcitabine exposure in PANC-1 cells. (B) GFPT2 expression was also significantly increased after gemcitabine exposure in control cells. This increase was also negated in SLP-2-suppressed cells. GAPDH was an internal control. All experiments were performed thrice. ${ }^{*} \mathrm{P}<0.05$ and ${ }^{* *} \mathrm{P}<0.01$. SLP-2, stomatin-like protein 2 ; GFPT2, glutamine-fructose-6-phosphate transaminase 2; RT-qPCR, reverse transcription-quantitative polymerase chain reaction; cont, control; sh, short hairpin; GEM, gemcitabine.

SLP-2 expression was increased at the site of liver metastasis. This confirmed that SLP-2 expression plays an important role in liver metastasis and that increased SLP-2 expression is linked to liver metastasis in PC, which may explain the poor prognosis.

SLP-2 has been revealed to regulate cell migration and invasion activities in several types of cancer. Dowling et al revealed that SLP-2 is one of the 16 most upregulated proteins in extremely invasive cancer cells, implying that SLP-2 may be active during cancer metastasis (35). However, the signaling pathway affecting cell migration and invasion activities differs according to the type of cancer. In liver cancer, SLP-2 expression was revealed to promote EMT progression (18). SLP-2 facilitated migration activity via regulating the $\mathrm{Wnt} / \beta$-catenin pathway in colorectal cancer (15). In glioma and liver cancer, SLP-2 was revealed to regulate cell motility via the NF- $\mathrm{BB}$ pathway, targeting MMP2 or MMP9 $(17,24)$. In the present study, to elucidate the mechanism in PC cells, microarray analyses were performed using SLP-2-suppressed PC cells. Among 15 candidate genes selected by the expression level of SLP-2, only GFPT2 was associated with cell death and glucose uptake activity. Therefore, GFPT2 was selected as an optimal new candidate genes regulated by SLP-2 expression to promote cell migration and invasion activities in PC cells.

GFPT2 is the first, and rate-limiting, enzyme of the hexosamine biosynthesis pathway (HBP). HBP is a branch of glucose metabolism that usually consumes approximately $2-5 \%$ of total glucose (36). It has also been revealed that GFPT2 is correlated with glucose uptake and is associated with glucose-driven metabolic pathways (32). Thus, increased GFPT2 expression could activate HBP by supplying the glucose itself and also by modulating the glucose substrate to this pathway. The HBP contributes to the provision of a substrate for glycosylation modification and has a wide range of effects on cellular function (32). Uridine diphosphate $\mathrm{N}$-acetylglucosamine (UDP-GlcNAc), an end-product of the HBP, is catalyzed by
$O$-GlcNAc transferase to form $O$-GlcNAc, which binds to serine/threonine residues of the target proteins in glycosylation modification (33). Increased $O$-GlcNAcylation can activate various cancer-related factors such as $\beta$-catenin (33), p53 (37), or c-Myc (38). In particular, $O$-GlcNAcylation of $\beta$-catenin enhances intranuclear $\beta$-catenin expression and facilitates signal activation, including EMT promotion and cancer invasion (33). Several previous studies have also demonstrated that GFPT2 can regulate cell migration and invasion activities by activating the EMT mechanism $(32,34)$. Therefore, high SLP-2 expression may promote cell motility by regulating HBP through GFPT2 expression. However, the present study presented no evidence of the HBP modulation in vitro or in vivo; hence, further metabolic studies are warranted to evaluate the role of SLP-2 in affecting the GFPT2 downstream pathway in HBP.

SLP-2 has been reported to be localized in mitochondria and upregulated under several conditions of mitochondrial stress (7). This increased expression plays an important role in SIMH, which promotes mitochondrial ATP production and leads to stress resistance in cells (39). Exposure to high concentrations of cisplatin was revealed to increase SLP-2 expression and induce an anti-apoptotic effect on cells (25). This response is one possible mechanism for stress-resistant regulation of SLP-2 expression. The present study revealed that SLP-2 expression was increased after NAC. When PC cells were exposed to gemcitabine, expression was increased for SLP-2 and GFPT2. Furthermore, GFPT2 expression was decreased in SLP-2-suppressed cells, even in a stressed condition (such as exposure to anticancer drug gemcitabine). All these data indicated that SLP-2 expression may be increased by chemotherapy itself; additionally, this increase may induce activation of the HBP through upregulation of GFPT2. Recently, several studies have raised the possibility of chemotherapy-induced metastasis (40) and have suggested that cancer cells tend to become metastatically aggressive following exposure to chemotherapy (41). Although SLP-2 
suppression did not alter chemosensitivity to gemcitabine, increased expression of SLP-2 after NAC may contribute to promoting liver metastasis. Further study should be conducted to investigate this hypothesis.

The present study has several limitations. First, only the function of SLP-2 was evaluated by inhibiting its expression. SLP-2 suppression did not significantly change the proliferation and chemosensitivity of PC cells to gemcitabine unlike previous findings $(24,42)$. Overexpression of SLP-2 increased the ability of cells to produce ATP, which is necessary for proliferation and resistance to stress $(11,23)$. Exposure of PC cells to gemcitabine also increased the expression of SLP-2, which may be a response to stress. Considering these data, overexpression may lead to diverse effects on cell functions. Second, the present study used G418 (geneticin) to select shRNA-transfected PC cells, and this agent may influence the growth and metabolism of cell lines (43). However, several examinations were performed, using two types of cell lines and two types of shRNA-transfected cell lines, to mitigate the effects of G418 and minimize this bias.

In conclusion, to the best of our knowledge, the present study is the first to analyze the effects of SLP-2 in PC. The results obtained herein demonstrated the involvement of SLP-2 in liver metastasis via regulation of the migration and invasion activities of PC cells. Furthermore, SLP-2 expression promoted glucose uptake activity and may regulate HBP, a branch of glucose metabolism, which can contribute to the activation of cancer cell motility. Furthermore, SLP-2 expression was increased under cytotoxic stress, implying that the aforementioned functions may be enhanced under the cellular stress caused by chemotherapy treatments. All these results indicated that the poor prognosis of high SLP-2 expression was caused by activated metastatic potential. Further investigations on HBP activation and its promotion of metastasis are warranted to determine whether these signals could provide novel therapeutic targets for PC.

\section{Acknowledgements}

Not applicable.

\section{Funding}

The present study was supported by KAKENHI Grants-in-Aid for young scientists (B) (grant no. K.A.16K19911).

\section{Availability of data and materials}

The data of microarray analysis are available in Gene Expression Omnibus at https://www.ncbi.nlm.nih. gov/geo/query/acc.cgi?acc=GSE162981 and can be accessed with GSE162981. The other datasets used and/or analyzed during this study are available from the corresponding author on reasonable request.

\section{Authors' contributions}

$\mathrm{DC}, \mathrm{KA}, \mathrm{HO}, \mathrm{KMi}$, XJY performed in vivo and in vitro analysis. KA, MM, TT, MI, KMa, SM, TMi, MM, KN, TMo, $\mathrm{TK}, \mathrm{MU}$ interpreted the patient data regarding the pancreatic ductal adenocarcinoma. SS and FF performed the pathological examination of the pancreatic ductal adenocarcinoma samples. KA, TT, MI, KMa, SM, TMi, MM, KN, TMo, TK, MU were major contributors in writing the manuscript. All authors read and approved the final manuscript.

\section{Ethics approval and consent to participate}

The Institutional Animal Experiment Committee of Tohoku University (Sendai, Japan) approved the present study protocol on September 20, 2017. The Institutional Review Board of Tohoku University (Sendai, Japan) approved the present study design on May 25, 2016 (2016-1-151). This was a retrospective study, therefore, the requirement for informed consent was waived and an opt-out method was used instead.

\section{Patient consent for publication}

Not applicable.

\section{Competing interests}

The authors declare that they have no competing interests.

\section{References}

1. Siegel RL, Miller KD, Goding Sauer A, Fedewa SA, Butterly LF, Anderson JC, Cercek A, Smith RA and Jemal A: Colorectal cancer statistics, 2020. CA Cancer J Clin 70: 145-164, 2020.

2. Neoptolemos JP, Stocken DD, Friess H, Bassi C, Dunn JA, Hickey H, Beger H, Fernandez-Cruz L, Dervenis C, Lacaine F, et al: A randomized trial of chemoradiotherapy and chemotherapy after resection of pancreatic cancer. N Engl J Med 350: 1200-1210, 2004.

3. Ariake K, Motoi F, Ohtsuka H, Fukase K, Masuda K, Mizuma M, Hayashi H, Nakagawa K, Morikawa T, Maeda S, et al: Predictive risk factors for peritoneal recurrence after pancreatic cancer resection and strategies for its prevention. Surg Today 47: 1434-1442, 2017.

4. Ariake K, Motoi F, Shimomura H, Mizuma M, Maeda S, Terao C, Tatewaki Y, Ohtsuka H, Fukase K, Masuda K, et al: 18-fluorodeoxyglucose positron emission tomography predicts recurrence in resected pancreatic ductal adenocarcinoma. J Gastrointest Surg 22: 279-287, 2018.

5. Yamamoto T, Sugiura T, Mizuno T, Okamura Y, Aramaki T, Endo $\mathrm{M}$ and Uesaka K: Preoperative FDG-PET predicts early recurrence and a poor prognosis after resection of pancreatic adenocarcinoma. Ann Surg Oncol 22: 677-684, 2015.

6. Hájek P, Chomyn A and Attardi G: Identification of a novel mitochondrial complex containing mitofusin 2 and stomatin-like protein 2. J Biol Chem 282: 5670-5681, 2007.

7. Da Cruz S, Parone PA, Gonzalo P, Bienvenut WV, Tondera D, Jourdain A, Quadroni M and Martinou JC: SLP-2 interacts with prohibitins in the mitochondrial inner membrane and contributes to their stability. Biochim Biophys Acta 1783: 904-911, 2008.

8. Mitsopoulos P, Chang YH, Wai T, König T, Dunn SD, Langer T and Madrenas J: Stomatin-like protein 2 is required for in vivo mitochondrial respiratory chain supercomplex formation and optimal cell function. Mol Cell Biol 35: 1838-1847, 2015.

9. Da Cruz S, De Marchi U, Frieden M, Parone PA, Martinou JC and Demaurex N: SLP-2 negatively modulates mitochondrial sodium-calcium exchange. Cell Calcium 47: 11-18, 2010.

10. Tondera D, Grandemange S, Jourdain A, Karbowski M, Mattenberger Y, Herzig S, Da Cruz S, Clerc P, Raschke I, Merkwirth C, et al: SLP-2 is required for stress-induced mitochondrial hyperfusion. EMBO J 28: 1589-1600, 2009.

11. Christie DA, Lemke CD, Elias IM, Chau LA, Kirchhof MG, Li B, Ball EH, Dunn SD, Hatch GM and Madrenas J: Stomatin-like protein 2 binds cardiolipin and regulates mitochondrial biogenesis and function. Mol Cell Biol 31: 3845-3856, 2011. 
12. Chang D, Ma K, Gong M, Cui Y, Liu ZH, Zhou XG, Zhou CN and Wang TY: SLP-2 overexpression is associated with tumour distant metastasis and poor prognosis in pulmonary squamous cell carcinoma. Biomarkers 15: 104-110, 2010.

13. Liu D, Zhang L, Shen Z, Tan F, Hu Y, Yu J and Li G: Increased levels of SLP-2 correlate with poor prognosis in gastric cancer. Gastric Cancer 16: 498-504, 2013.

14. Li XH, He F, Yan SM, Li Y, Cao Y, Huang CY and Zhou ZW: Increased expression of stomatin-like protein 2 (STOML2) predicts decreased survival in gastric adenocarcinoma: A retrospective study. Med Oncol 31: 763, 2014.

15. Zhou C, Li Y, Wang G, Niu W, Zhang J, Wang G, Zhao Q and Fan L: Enhanced SLP-2 promotes invasion and metastasis by regulating $\mathrm{Wnt} / \beta$-catenin signal pathway in colorectal cancer and predicts poor prognosis. Pathol Res Pract 215: 57-67, 2019.

16. Wang WX, Lin QF, Shen D, Liu SP, Mao WD, Ma G and Qi WD: Clinicopathological significance of SLP-2 overexpression in human gallbladder cancer. Tumour Biol 35: 419-423, 2014.

17. Zhu W, Li W, Geng Q, Wang X, Sun W, Jiang H and Pu X: Silence of stomatin-like protein 2 represses migration and invasion ability of human liver cancer cells via inhibiting the nuclear factor kappa B (NF-kB) pathway. Med Sci Monit 24: 7625-7632, 2018.

18. Huang Y, Chen Y, Lin X, Lin Q, Han M and Guo G: Clinical significance of SLP-2 in hepatocellular carcinoma tissues and its regulation in cancer cell proliferation, migration, and EMT. OncoTargets Ther 10: 4665-4673, 2017.

19. Cao W, Zhang B, Li J, Liu Y, Liu Z and Sun B: SLP-2 overexpression could serve as a prognostic factor in node positive and HER2 negative breast cancer. Pathology 43: 713-718, 2011

20. Zhang J, Song X, Li C and Tian Y: Expression and clinical significance of SLP-2 in ovarian tumors. Oncol Lett 17: 4626-4632, 2019.

21. Deng H, Deng Y, Liu F, Chen J, Li Z, Zhao K, Guan X and Liang W: Stomatin-like protein 2 is overexpressed in cervical cancer and involved in tumor cell apoptosis. Oncol Lett 14: 6355-6364, 2017.

22. Qu H, Jiang W, Wang Y and Chen P: STOML2 as a novel prognostic biomarker modulates cell proliferation, motility and chemo-sensitivity via IL6-Stat3 pathway in head and neck squamous cell carcinoma. Am J Transl Res 11: 683-695, 2019.

23. Wang Y, Cao W, Yu Z and Liu Z: Downregulation of a mitochondria associated protein SLP-2 inhibits tumor cell motility, proliferation and enhances cell sensitivity to chemotherapeutic reagents. Cancer Biol Ther 8: 1651-1658, 2009.

24. Song L, Liu L, Wu Z, Lin C, Dai T, Yu C, Wang X, Wu J, Li M and $\mathrm{Li}$ J: Knockdown of stomatin-like protein 2 (STOML2) reduces the invasive ability of glioma cells through inhibition of the NF-кB/MMP-9 pathway. J Pathol 226: 534-543, 2012.

25. Hu G, Zhang J, Xu F, Deng H, Zhang W, Kang S and Liang W: Stomatin-like protein 2 inhibits cisplatin-induced apoptosis through MEK/ERK signaling and the mitochondrial apoptosis pathway in cervical cancer cells. Cancer Sci 109: 1357-1368, 2018.

26. Takadate T, Onogawa T, Fukuda T, Motoi F, Suzuki T, Fujii K Kihara M, Mikami S, Bando Y, Maeda S, et al: Novel prognostic protein markers of resectable pancreatic cancer identified by coupled shotgun and targeted proteomics using formalin-fixed paraffin-embedded tissues. Int J Cancer 132: 1368-1382, 2013.

27. Livak KJ and Schmittgen DT: Analysis of relative gene expression data using real-time quantitative PCR and the 2(-Delta Delta C(T)) method. Methods 25: 402-408, 2001.

28. National Comprehensive Cancer Network. NCCN practice guidelines for pancreatic cancer, Version 1. (2020). https://www.ncen. org/professionals/physician_gls/PDF/pancreatic.pdf. Access date September 1,2020.

29. UICC: TNM Classification of Malignant Tumours, 7th edition, Sobin LH, Gospodarowicz MK an Wittekind C (eds). Wiley Blackwell, Hoboken, 2009.
30. von Elm E, Altman DG, Egger M, Pocock SJ, Gøtzsche PC and Vandenbroucke JP; STROBE Initiative: The strengthening the reporting of observational studies in epidemiology (STROBE) statement: Guidelines for reporting observational studies. J Clin Epidemiol 61: 344-349, 2008

31. Suemizu H, Monnai M, Ohnishi Y, Ito M, Tamaoki N and Nakamura M: Identification of a key molecular regulator of liver metastasis in human pancreatic carcinoma using a novel quantitative model of metastasis in NOD/SCID/gammacnull (NOG) mice. Int J Oncol 31: 741-751, 2007.

32. Zhang W, Bouchard G, Yu A, Shafiq M, Jamali M, Shrager JB, Ayers K, Bakr S, Gentles AJ, Diehn M, et al: GFPT2-expressing cancer-associated fibroblasts mediate metabolic reprogramming in human lung adenocarcinoma. Cancer Res 78: 3445-3457, 2018.

33. Zhou L, Luo M, Cheng LJ, Li RN, Liu B and Linghu H: Glutamine-fructose-6-phosphate transaminase 2 (GFPT2) promotes the EMT of serous ovarian cancer by activating the hexosamine biosynthetic pathway to increase the nuclear location of $\beta$-catenin. Pathol Res Pract 215: 152681, 2019.

34. Szymura SJ, Zaemes JP, Allison DF, Clift SH, D'Innocenzi JM, Gray LG, McKenna BD, Morris BB, Bekiranov S, LeGallo RD, et al: NF- $\mathrm{B}$ upregulates glutamine-fructose-6-phosphate transaminase 2 to promote migration in non-small cell lung cancer. Cell Commun Signal 17: 24, 2019.

35. Dowling $\mathrm{P}$, Walsh $\mathrm{N}$ and Clynes $\mathrm{M}$ : Membrane and membrane-associated proteins involved in the aggressive phenotype displayed by highly invasive cancer cells. Proteomics 8: 4054-4065, 2008.

36. Marshall S, Bacote V and Traxinger RR: Discovery of a metabolic pathway mediating glucose-induced desensitization of the glucose transport system. Role of hexosamine biosynthesis in the induction of insulin resistance. J Biol Chem 266: 4706-4712, 1991.

37. Yang WH, Kim JE, Nam HW, Ju JW, Kim HS, Kim YS and Cho JW: Modification of $\mathrm{p} 53$ with O-linked N-acetylglucosamine regulates p53 activity and stability. Nat Cell Biol 8: 1074-1083, 2006.

38. Itkonen HM, Minner S, Guldvik IJ, Sandmann MJ, Tsourlakis MC, Berge V, Svindland A, Schlomm T and Mills IG: O-GlcNAc transferase integrates metabolic pathways to regulate the stability of c-MYC in human prostate cancer cells. Cancer Res 73: 5277-5287, 2013.

39. Ghose P, Park EC, Tabakin A, Salazar-Vasquez N and Rongo C: Anoxia-reoxygenation regulates mitochondrial dynamics through the hypoxia response pathway, SKN-1/Nrf, and stomatin-like protein STL-1/SLP-2. PLOS Genet 9: e1004063, 2013.

40. Karagiannis GS, Condeelis JS and Oktay $\mathrm{MH}$ : Chemotherapy-induced metastasis: Mechanisms and translational opportunities. Clin Exp Metastasis 35: 269-284, 2018.

41. Shah AN, Summy JM, Zhang J, Park SI, Parikh NU and Gallick GE: Development and characterization of gemcitabine-resistant pancreatic tumor cells. Ann Surg Oncol 14: 3629-3637, 2007.

42. Yang CT, Li JM, Li LF, Ko YS and Chen JT: Stomatin-like protein 2 regulates survivin expression in non-small cell lung cancer cells through $\beta$-catenin signaling pathway. Cell Death Dis 9: 425, 2018.

43. Yallop CA and Svendsen I: The effects of G418 on the growth and metabolism of recombinant mammalian cell lines. Cytotechnology 35: 101-114, 2001.

(i) $(-)$ This work is licensed under a Creative Commons Attribution-NonCommercial-NoDerivatives 4.0 International (CC BY-NC-ND 4.0) License. 